\title{
A INFLUÊNCIA DA MÍDIA NA INSTRUMENTALIZAÇÃ̃ E COISIFICAÇÃO DA MULHER: UMA VIOLAÇÃO DE DIREITOS HUMANOS
}

\author{
Camyla Galeão de Azevedo* \\ Fádia Yasmin Costa Mauro**
}

Resumo: Este estudo, por intermédio de pesquisa bibliográfica, busca discutir a influência da mídia na instrumentalização e coisificação da mulher. Através dos meios de comunicação, mediante a disseminação do alcance de um padrão de beleza ideal, as mulheres são coisificadas e estereotipadas. Além de serem coisificadas, sofrem violação de direitos humanos, através da violência psicológica proferida contra elas, de acordo com a Convenção de Belém do Pará, praticada pelos meios de comunicação. Através dessa disseminação, muitas mulheres dispendem seu tempo e seu dinheiro, e entram num caminho sem fim: a busca de um padrão ideal de beleza.

Palavras-chave: Mulher, Mídia, Direitos Humanos, Convenção de Belém do Pará, Violência Psicológica.

\section{THE INFLUENCE OF THE MEDIA IN THE INSTRUMENTALIZATION AND THE COHESIFICATION OF WOMEN: A VIOLATION OF HUMAN RIGHTS}

\begin{abstract}
This study, through a bibliographical research, seeks to discuss the influence of the media in the instrumentalization and comparison of women. Through the media, by disseminating the reach of a pattern of ideal beauty, women are haggard and stereotyped. In addition to being condemned, they suffer violations of human rights through the psychological violence against them, in accordance with the Convention of Belém do Pará, practiced by the media. Through this dissemination, many women spend their time and money, and enter an endless path: the search for an ideal pattern of beauty.
\end{abstract}

Keywords: Women, Media, Human Rights, Belém do Pará Convention, Psychological Violence.

\footnotetext{
* Advogada. Mestranda em Direito, Políticas Públicas e Desenvolvimento Regional no Centro Universitário do Pará, com previsão de conclusão no ano de 2020, (aprovada em primeiro lugar no processo seletivo). Graduada em Direito pelo Centro Universitário do Estado do Pará- CESUPA. Monitora de Direito Administrativo no período de janeiro de 2016 até dezembro de 2016. Integrante do Grupo de Pesquisa Democracia, Poder Judiciário e Direitos Humanos e do Grupo de Estudos Feministas no Centro Universitário do Estado do Pará- CESUPA.

** Mestranda em Direito, na área de concentração Direitos Humanos e na linha de pesquisa Direitos Humanos e Inclusão Social, pelo Programa de Pós-Graduação em Direito do Instituto de Ciências Jurídicas da Universidade Federal do Pará (2017-presente). Advogada (2016-presente). Membro e Secretária da Comissão de Proteção à Pessoa Com Deficiência da OAB/PA (2016-presente). Graduada em Direito pelo Centro Universitário do Estado do Pará (2016).
}

Rev. de Gênero, Sexualidade e Direito | e-ISSN: 2525-9849 | Porto Alegre | v. 4 | n. 2 | p. 119 -136 | Jul/Dez. 2018 


\section{INTRODUÇÃO}

Desde os primórdios, convive-se com a sociedade patriarcal, aquela que é determinada pela separação de papeis de gênero e subjugação da mulher ao homem, seja no âmbito familiar, quando ainda não casada, seja no matrimônio, quando atrelada a outro homem, que executará o papel de marido e gestor do lar. É um cenário combatido fortemente pelas lutas feministas, pela conquista de direitos civis e políticos da primeira onda, pelo direito ao próprio corpo na segunda onda e pelas vivências diferenciadas entre as mulheres.

Em reforço a isso, a mídia e a publicidade sempre estiveram no percalço da mulher, fazendo com a dominação fosse reverberada através de padrões de conduta, padrões estéticos, ideais de mulheres perfeitas, dóceis ou então, nos dias atuais, da mulher magra, sexual, com traços finos e curvilínea.

Deste modo, em que pese mulheres estarem em constante busca pela sua existência em espaços públicos e privados, nas relações de poder, ainda se encontram atrofiadas a um ideal de pertença sexual, dos atributos que as farão sentir aceitas, belas e atrativas ao sexo oposto, o que tem aumentado os índices de depressão, baixa estima, procedimentos estéticos e cirúrgicos, no intuito de alcançar os ideais "universais" de beleza.

Alerta Zúñiga (2010) que essa cidadania moderna e liberal acaba por retratar uma individualidade despida de atributos sociais, cuja única característica para concessão de direitos é o fato de pertença a espécie humana e alerta para uma exclusão feminina em razão da "naturalização" de uma desigualdade entre os sexos que permita a invisibilidade da mulher e uma constante misoginia na representação desta na ciência, literatura e outras formas culturais.

O que se pretende demonstrar neste artigo, é como a mídia possui um papel crucial na instrumentalização e coisificação da mulher, na reverberação do "Mito da Beleza", e como esta constitui uma forma de violação de direitos humanos da mulher, da sua identidade, capaz de perpetuar violência contra mulher e a manutenção de papéis de gênero e dominação.

A análise se justifica pelos perigos à integridade e dignidade da mulher que representam tais discursos midiáticos dentro do contexto sócio-político em que a mulher está inserida. Isso porque Merry (2006) questiona se os direitos humanos, dentre eles a proteção da mulher e sua integridade, são novas e poderosas ferramentas de resistência para os movimentos sociais e políticos, como o feminismo, ou se servem apenas como forma de submetê-los ao domínio do Estado? 
Desta feita, este trabalho desenvolverá uma revisão literária e teórica sobre a influência da mídia no processo de instrumentalização do corpo da mulher, como isso fere direitos humanos e como se desfazer da ideia do "mito da beleza", evitando-se com isso corroborar com a proliferação de padrões estéticos e estereótipos e com uma cultura de subjugação do sexo feminino, pautada na hierarquização de padrões de gênero e na socialização de uma masculinidade que dita os padrões e uma feminilidade submissa, que precisa alcançar o intangível.

Assim, a metodologia a ser adotada é eminentemente teórica, fazendo-se uma análise de autoras chaves para o entendimento da proposta como Rachel Moreno e Naomi Wolf, para explicar como padrões estéticos de beleza, mídia e consumo estão relacionados com a violação de direitos humanos da mulher e da manutenção de estruturas de poder e de subjugação do gênero feminino.

O texto discutirá a mulher inserida no contexto midiático, posteriormente falar-se-á acerca dos direitos humanos da mulher, principalmente os atinentes a questão estética contida na Convenção de Belém, e por fim, sobre o "Mito da Beleza" e como este está relacionado com a instrumentalização da mulher na mídia e na manutenção de uma subjugação, ainda que sob a ótica moderna, do corpo da mulher para o homem.

\section{MÍDIA E MULHER}

A chegada da modernidade, trouxe consigo nos últimos anos, a presença marcante da mídia. Primeiramente, os rádios, com menor influência em nossas vidas atualmente, a televisão, com presença marcante nos lares brasileiros, bem como a explosão da internet através das redes sociais.

A internet e as redes sociais vieram ganhando um maior espaço, se comparadas ao rádio e a televisão nos últimos anos. Os meios de comunicações virtuais são aqueles que atraem mais os jovens, proporcionam um maior conhecimento e maior confiabilidade entre os consumidores. Apesar de ter ganhado espaço ao longo dos anos, a televisão ainda se faz mais do que presente nos lares brasileiros. Elas estão presentes por todos os cômodos das casas: na sala de estar, sala de jantar, sala de TV e nos quartos (MORENO, 2017, p. 29).

Além de entretenimento, as televisões com suas programações diárias, não só entretêm as pessoas, mas doutrinam-nas, organizam o seu dia a dia. As famílias de hoje preferem que as 
crianças fiquem sentadas na frente da televisão do que saiam para brincar nas ruas, subam em árvores e brinquem com os amigos. Alienados, ficam o dia inteiro no sofá da sala assistindo televisão, consumindo alimentos nocivos à saúde altamente divulgados pelas mídias, provocando o sedentarismo e a obesidade infantil. "A refeição se acelera para dar espaço à novela. A conversa familiar míngua e se estiola” (MORENO, 2017, p. 30).

Assim, os meios de comunicação doutrinam, ditam e organizam a vida das pessoas, provocando impactos diretos na formação dos gêneros, em sua discriminação, bem como e, principalmente, em sua visualização pela sociedade, advinda dos meios de comunicação.

A presença das mulheres na mídia, seja em redes televisivas ou em redes sociais, é abundante. Entretanto, a presença delas é focada sempre em uma forma e um biotipo similar. Apesar das transformações ao longo dos anos, hoje visualizamos mulheres como protagonistas de novelas, âncoras de jornais nacionais, apresentadora de programas e diversas outras funções que lhe são concedidas dentro do mundo televisivo. Entretanto, a forma como são inseridas e repassadas para o público demonstra um certo perfil entre as mulheres. Geralmente, visualizamos repórteres sempre jovens e belas, com a pele impecável e magras. Ao apresentarem sinais de envelhecimento, são rapidamente substituídas por outras mais jovens. Estão sempre bem arrumadas, maquiadas, bem vestidas e belas (MORENO, 2017).

Além de formadoras de opiniões, já que elas "dão a ultima palavra, qualificam os entrevistados, nos dizem como reagir e interpretar os fatos que mostram, num processo de sedutora intimidação social e cultural, como diz a filósofa Marilena Chaú em suas obras" (MORENO, 2017, p. 31), são também formadoras de beleza e de estilo. Na mídia impressa a imagem da mulher é repassada como uma musa inspiradora, isso é facilmente perceptível através da análise das propagandas de carros, restaurantes e negócios. Sempre haverá mulheres belas e magras por trás da venda do negócio.

O discurso midiático apresenta-se quase sempre expondo mulheres brancas (poucas vezes mulheres negras estão em posição de destaque), sempre jovens, sempre magras, com a maioria delas de cabelos loiros e, preferencialmente, lisos (poucas vezes os ondulados e raramente os cacheados).

A partir da apresentação desses estereótipos, é possível observar que há a venda de valores, de beleza estereotipada (beleza midiática), como o caminho para o alcance da felicidade. Como menciona a autora Cythia Vianna (2005), o perfil e o biótipo da mulher brasileira não condizem com a realidade repassada pela mídia, levando as mulheres brasileiras 
realizarem medidas extremas para conseguir um padrão de beleza considerado "perfeito", entretanto, raramente alcançado.

Partindo-se deste contexto, muitas mulheres superendividam-se, afundam-se em dívidas realizando tratamentos estéticos para alcançar o ideal de beleza repassado pelos meios televisivos e virtuais, nunca alcançando a beleza perfeita, o que acaba por se tornar um ciclo vicioso. Sempre buscam mais e mais tratamentos estéticos para tentar chegar a esse ideal.

Como mencionado, mesmo após tratamentos e cirurgias plásticas, a beleza ideal nunca chega e, consequentemente, a felicidade também não. Com isso, geram-se inúmeras consequências como a baixa de autoestima, já que muitas mulheres não se conformam com o padrão estético que efetivamente possuem, bem como doenças como ansiedade, bulimia e anorexia, para tentar alcançar o corpo dos sonhos.

Ao longo dos anos, a beleza esteve cada vez mais interligada à magreza. Ser bonita é ser magra. Ser gorda é ser feia, mal cuidada. Segundo Vianna, o padrão de beleza atual é totalmente diferente do padrão de beleza de cinquenta anos atrás. Segundo Vianna (2005), a garota White Rock media 1,60 metros e pesava $63 \mathrm{~kg}$. Atualmente ela mede 1,50 metros e pesa $50 \mathrm{~kg}$. Para os padrões atuais, Marilyn Monroe, pois mais bela que fosse, seria considerada gorda (VIANNA, 2005).

A cada ano que passa, o padrão de beleza vai mais além da magreza, preconizando um corpo esquelético. Como mencionado, a busca por esse padrão de magreza provoca inúmeros distúrbios psicológicos e alimentares, entretanto, por outro lado, há uma grande preocupação com o grau de obesidade no Brasil. Há um verdadeiro paradoxo, em que corpos magros e esqueléticos são disseminados como espelhos a serem seguidos pela mídia, enquanto a população está realmente cada vez mais obesa. A solução do capitalismo como forma de aproveitar esse paradoxo é aproveitar os meios de comunicação com “dietas milagrosas", que provocam o emagrecimento de forma abusiva, prejudicial à saúde da mulher. Dietas essas que são vendidas facilmente em revistas que preconizam a "boa forma" ou em sites relacionados à beleza, sem qualquer tipo de orientação nutricional ou médica. Assim, menciona Cynthia Vianna: “em todo veículo voltado para as mulheres há diversos anúncios de produtos dietéticos ou com valores calóricos reduzidos, além de matérias com dietas (muitas delas restritivas demais ou sem fundamento científico) e fórmulas milagrosas para emagrecimento" (VIANNA, 2005, p. 7). 
Uma pesquisa realizada pela Secretaria de Estado da Saúde revelou em 77\% dos jovens em São Paulo apresentam algum tipo de propensão a um distúrbio alimentar como bulimia, anorexia ou compulsão alimentar. Entre as mulheres participantes, 85\% disseram que acreditam na existência de um padrão de beleza imposto pela sociedade, $46 \%$ das entrevistadas afirmaram que mulheres magras são mais felizes e 55\% adorariam acordar magras. Em análise realizada recentemente pela Secretaria de Saúde afirmou que a cada dois dias, em média, uma pessoa é internada com anorexia ou bulimia nos hospitais do Sistema único de Saúde (SUS) em São Paulo. Nos sete meses de 2013, observou-se 97 internações devido a distúrbios alimentares. (GOVERNO DO ESTADO DE SÃO PAULO, online, 2014).

Em pesquisa realizada pela Escola Superior de Propaganda e Marketing- ESPM (2007), mulheres desejam uma beleza que seja menos estreita àquela divulgada pela mídia, desejam algo mais próximo de suas realidades. Das mulheres entrevistadas, apenas metade se diz estar razoavelmente satisfeita com seus corpos. Mais de $75 \%$ das mulheres não se sentem confortáveis para se considerarem belas. Segundo dados levantados na pesquisa:

Os dados mostram que a maioria das mulheres está insatisfeita com sua beleza e atratividade física. Para elas o peso e a forma do corpo ainda incomodam. As mulheres japonesas têm o maior índice de insatisfação física (59\%), seguidas pelas brasileiras (37\%), inglesas e norte-americanas (36\%), argentinas $(27 \%)$ e holandesas $(25 \%)$. Tudo indica que essa situação está relacionada a preceitos da cultura popular que constrói alguns valores de atratividade física muito distantes do que é possível encontrar na sociedade industrial contemporânea. $\mathrm{O}$ estudo revelou também que as mulheres têm consciência disso e resistem a essa imposição. Um dado relevante, proveniente da Sociedade Internacional de Cirurgia Plástica Estética revela que Estados Unidos, México e Brasil lideram o ranking mundial de cirurgia plástica no mundo (ESPM, 2007, p. 6).

As telenovelas são também uma das principais disseminadoras e incentivadoras do consumo para as mulheres. De acordo com Heloisa Buarque de Almeida, o maior público espectador desses programas são as mulheres. Há uma grande concorrência entre as marcas multinacionais e nacionais para fazer publicidade nas novelas. A justaposição de imagens em tons publicitários também influencia no poder e no querer de compra das mulheres. Esses programas permitem promover uma infinidade de bens e serviços que "facilitam" a rotina da mulher independente, que tem sua família e trabalha fora de casa. Direciona-se a mulher que é independente, mas que nunca deixa de ser uma boa esposa, mãe, dona-de-casa, além de ser bela 
e de se cuidar. Apresenta produtos que estão ao seu alcance e que toda mulher precisa ser para ser bem cuidada, independente e feliz (ALMEIDA, 2007, p. 189).

Há, na verdade, uma democratização do consumo e, consequentemente, da beleza (LIPOVETSKY, 2007). O consumo da modernidade, segundo Gilles Lipovetsky, é traduzido pela busca do bem-estar, da qualidade de vida, de sentir-se bem consigo mesmo, de buscar as suas satisfações pessoais. A partir do momento que o consumo se democratiza, a beleza também sofre esse processo, produzindo a ideia de que a beleza está ao alcance de todas.

Centenas de instrumentos garantem os preços e as condições de pagamento do produto. Como menciona Rachel Moreno (2017), hoje só não é bela quem não tem vaidade. Conjuntamente com a democratização da beleza, surgiu a ditadura do peso. Hoje, os mecanismos para o emagrecimento estão disponíveis para todas: procedimentos estéticos, medicamentos, cirurgias plásticas e o excesso de exercícios físicos. Ao mesmo tempo, somente é gorda quem é considerada relaxa, ou mulheres que compensam suas frustações na comida.

O consumo democratizou-se, juntamente com a facilitação nas formas de pagamento dos produtos, em que as pessoas se endividam em extensas parcelas todos os meses. $\mathrm{O}$ consumidor de hoje, segundo Lipovetsky (2007), é um hiperconsumidor. Aquele que busca bem-estar, qualidade de vida e, principalmente, independência. A independência é um dos principais paradigmas repassados pela mídia na atualidade. Nesse diapasão, a imagem repassada pela mídia é de uma mulher independente e bela. Busca-se a beleza para alcançar a independência. Entretanto, até que ponto o consumo, conjuntamente com a mídia, proporciona, efetivamente, independência para as mulheres?

Somos realmente independentes e, consequentemente, felizes? Há um verdadeiro paradoxo na felicidade da modernidade. As mulheres entram num caminho, em busca da verdadeira independência e felicidade, mas esse caminho não tem fim. Cada vez mais as mulheres são reféns do consumo e reféns da busca de um padrão ideal de beleza, disseminado pela mídia (LIPOVETSKY, 2007).

\section{DIREITOS HUMANOS E A IMAGEM FEMININA}

Em 1990 foi deflagrado um processo de consulta em âmbito interamericano sobre a situação envolvendo violência e mulher. A consulta teve por objetivo, iniciar a investigação e sistematização de propostas para regulamentar, a partir de legislações específicas, a violência 
contra as mulheres nas Américas, tendo em vista a sua grande ocorrência. A partir da análise da consulta, verificou-se que havia um predomínio em âmbito universal das diversas formas e manifestações de violência contra a mulher, justificando, portanto, em nível internacional, mecanismos que combatam e previnam essa violência (OLIVEIRA, 2017).

Em 1994, a Comissão Interamericana das Mulheres- CIM aprovou um projeto que buscava realizar o combate e a defesa das mulheres, frente a este quadro de constante violência. A CIM apresentou, portanto, a Convenção Interamericana para Prevenir, Punir e Erradicar a Violência Contra a Mulher, sendo esse apresentado na Assembleia Geral da OEA, em Belém do Pará. Por este motivo, a convenção também é chamada de Convenção de Belém do Pará (OLIVEIRA, 2017).

A Convenção de Belém do Pará representou um verdadeiro marco jurídico contra a violência da mulher mundialmente. Até o ano de 2017, o tratado foi ratificado por 32 países da OEA, inclusive o Brasil, o qual ratificou em 1994.

Como mencionado, a Convenção de Belém do Pará busca combater a violência contra as mulheres, com base ao respeito aos direitos humanos, consagrado na Declaração Americana dos Direitos e Deveres do Homem e na Declaração Universal dos Direitos Humanos, bem como em outros tratados internacionais e regionais. Reconhece que a violência contra a mulher constitui uma violação aos direitos humanos e as liberdades fundamentais, obstaculizando total ou parcialmente, o exercício desses direitos e liberdades. Através do tratado, buscam a eliminação da violência contra a mulher como condição indispensável para o seu próprio desenvolvimento individual e social e sua plena e igualitária participação em todas as esferas de vida (COMISSÃO INTERAMERICANA DE DIREITOS HUMANOS, 1994).

Diferentemente de outros tratados internacionais, a Convenção de Belém do Pará entende por violência contra a mulher não somente a violência física, mas qualquer ato ou conduta baseada no gênero, que cause morte, dano ou sofrimento físico, sexual e psicológico à mulher, tanto na esfera pública quanto na esfera privada. Para efeitos do objeto deste trabalho, nos deteremos tão somente no sofrimento psicológico atribuído à mulher (CONVENÇÃO DE BELÉM DO PARÁ, art. $1^{\circ}$, pág. 1).

$\mathrm{O}$ art. $4^{\circ}$ da convenção diz que toda mulher tem direito ao reconhecimento e exercício de direitos humanos e liberdades consagradas em diversos tratados internacionais e regionais, abrangendo o direito a integridade mental e moral. $\mathrm{O}$ artigo $6^{\circ}$ nos indica que toda mulher tem direito de ser livre da violência, abrangendo o direito de a mulher ser livre a todas as formas de 
discriminação, e o direito de a mulher ser valorizada e educada livre de padrões estereotipados de comportamento e costumes sociais e culturais baseados em conceitos de inferioridade e subordinação:

\section{$\underline{\text { Artigo } 6}$}

O direito de toda mulher a ser livre de violência abrange, entre outros:

a. o direito da mulher a ser livre de todas as formas de discriminação; e

b. o direito da mulher a ser valorizada e educada livre de padrões estereotipados de comportamento e costumes sociais e culturais baseados em conceitos de inferioridade ou subordinação. (BRASIL/ CIDH, 1994).

$\mathrm{Na}$ sociedade hierarquizada, patriarcal e discriminatória em que vivemos, a discriminação e diferenciação entre os gêneros é a realidade. Por este motivo, nos termos da alínea a do art. $6^{\circ}$ da convenção, toda mulher é livre para viver sua vida, sem qualquer tipo de discriminação. A alínea $b$, totalmente relacionado com o objeto deste estudo, diz respeito ao direito de a mulher ser educada, valorizada livre de padrões estereotipados de comportamento e costumes baseados em conceito de inferioridade e subordinação.

Tal alínea relaciona-se totalmente com a imagem criada da mulher na sociedade, de que a mulher chega para embelezar o ambiente (VIANNA, 2005), de que a mulher é delicada, doce e frágil. Essas características são características que lhes são impostas de forma impositiva e estereotipada, no sentido de que toda mulher que se preze, precisa seguir uma cartela de padrões estereotipados para ser uma mulher de valor, de qualidade e, consequentemente, reconhecida pela sociedade.

$\mathrm{O}$ artigo $8^{\circ}$ da convenção, estipula as medidas que deverão ser adotadas pelos Estados para erradicar toda e qualquer forma de violência contra a mulher. Na alínea "g" do mesmo artigo, está a necessidade de o Estado adotar medidas que incentivem os meios de comunicação de modo que estes formulem diretrizes adequadas de divulgação, contribuindo para a erradicação da violência contra a mulher em todas as suas formas e enalteçam o respeito pela dignidade da mulher.

Como mencionado no primeiro capítulo deste trabalho, os meios de comunicação, conjuntamente com a mídia e modelo capitalista como um todo, criam simultaneamente uma imagem estereotipada da mulher, ligada a certas características estereotipadas e padronizadas que lhes são automaticamente impostas. Esse mecanismo pode ser verificado através da constante necessidade de a mulher alcançar um padrão ideal de beleza, através da magreza por 
exemplo, acabando por afundar-se em dívidas, em busca do caminho da felicidade, caminho este que não possui um fim.

Frente a toda essa problemática, questiona-se: a mídia, em um contexto geral, conjuntamente com os meios de consumo, valoriza efetivamente a mulher livre de padrões estereotipados? A mídia, efetivamente, pratica violência psicológica contra a mulher? São questões de suma importância que serão discutidas, a partir do referencial teórico apresentado, no próximo tópico.

\section{3 “O MITO DA BELEZA": COISIFICAÇÃO DA MULHER NA MÍDIA ENQUANTO QUESTÃO VIOLADORA DE DIREITOS HUMANOS}

Como bem representado ao longo desde texto, a publicidade e propaganda midiática, desde de seus primórdios reproduziu imagens estereotipadas, discriminatórias e que de algum modo, ofendem a dignidade da mulher. Se em outra época, o ideal da beleza era representado pela mulher do lar, recatada, submissa e "prendada", nas duas últimas décadas principalmente, essa imagem tem dado espaço a uma sexualização exacerbada do corpo, do feminino.

A mercantilização do corpo da mulher, transformada pela mídia em "musa", "magra", “curvilínea”, representa o desnível em uma sociedade que pretende ser democrática, justa e igualitária. Demonstra que há uma hierarquia, onde o corpo da mulher é instrumento de sexualização para a venda, satisfação e outras formas de ataque a sua própria dignidade.

Wolf (2018, p. 25) alerta que, em um mundo onde tecnicamente mulheres possuem todos os direitos, como voto e trabalho, preocupar-se em grande escala com questões relativas a aparência parecem triviais e supérfluas. As mulheres convivem com sentimentos de vergonha, culpa e negação sobre seus próprios corpos despadronizados, questionando-se o porquê de sua constante e existente "neurose" com seus aspectos estéticos.

Isso porque, em que pese mulheres estarem constantemente lutando para engendrar-se nas estruturas de poder, paralelo a isso é também seu desejo do alcance da perfeição, do belo. Assim, crescem em ritmo acelerado as cirurgias plásticas, transtornos alimentares e índices de depressão, suicídio e baixa estima.

Pesquisas recentes revelam com consistência que, no mundo ocidental, entre a maioria das mulheres que trabalham, têm sucesso, são atraentes e equilibradas, existe uma "subvida" secreta que envenena nossa liberdade: impregnada de conceitos de beleza, ela é um escuro filão de ódio a nós 
mesmas, obsessões com o físico, pânico de envelhecer e pavor de perder o controle. (WOLF, 2018, p. 26)

Não é injusto afirmar que a mídia desenvolve um papel estelar nesse cenário da instrumentalização e coisificação da mulher. $\mathrm{O}$ mito da beleza é um forte opositor ao senso de feminismo, enquanto deixa-se para trás a domesticidade, a castidade e passividade, esse mito vem reafirmar estruturas de poder seculares através de uma nova forma de submissão: o parâmetro da feminilidade bem-sucedida.

Esse parâmetro diz que mulheres devem, não só trabalhar, como também manter uma imagem pessoal que seja aprazível socialmente, devem apresentar corpos esbeltos, magros e dignos de serem apreciados pelo público masculino.

Em "Mística Feminina" (1971), Betty Friedan denunciava o retorno da mulher ao lar, após conquistas de direitos civis pelas feministas norte-americanas. Em uma de suas personagens Lucy, o retrato da inconformidade e da emersão da revolução da mulher:

Discursava sobre a abolição aos sábados e domingos, como agente da Sociedade Anti-Escravagista, e pelos direitos da mulher no resto da semana, por conta própria - enfrentando e dominando homens que a ameaçavam com cacetes, que lançavam contra ela ovos e livros de oração e, certa vez, em pleno inverno, até a água gelada de uma mangueira, através da janela. (FRIEDAN, 1971, págs. 78 e 79).

Tal passagem mostra a real caminhada enfrentada por mulheres reais que não aceitavam a condição da sociedade patriarcal em que estavam inseridas, como meras reprodutoras, subjugadas primeiro ao mando do pai, e depois aos desejos do marido. As pioneiras da teoria feminista, lutaram pela busca de cidadania, do direito de competir no mercado profissional e decidir o próprio destino. Em um passado de retrocessos e vitórias, todavia, a construção social de uma imagem de mulher objeto, de contornos apelativos, ou seja, a figura de um corpo sexuado, se mostrou uma nova preocupação ao movimento feminista (TORRECILHA, 2014).

Eis o paradigma do "Mito da Beleza", é julgar que o sentimento de belo é algo que pode ser qualificado como objetivo e universal. Mulheres devem possuir tais atributos, elencados por uma cultura midiática e social, e homens devem querer estar com mulheres que contenham esses caracteres. Assim, a encarnação do belo é uma obrigação para a mulher, situação essa necessária e natural por ser biológica, sexual e evolutiva. (WOLF, 2018).

A beleza torna-se um padrão monetário, que é determinado pela política, economia e cultura. No mundo ocidental, isto é feito conjuntamente e o instrumento é a mídia, que 
constantemente através dos veículos de informações, cada vez mais rápidos e tecnológicos, constroem uma hierarquia, padrões físicos que estabelecem relações de poder nas quais mulheres precisam competir de forma antinatural consigo e entre si para obter os recursos necessários para o alcance desses estereótipos.

Bento (2007) questiona esses valores que são transmitidos pela indústria midiática que reduz a mulher e a subjuga a um papel um papel de submissão e coisificação, submissão não mais a alguém propriamente dito, mas a um objetivo intangível de beleza.

O marqueteiro misógino supõe que sua obra-prima apenas retrata uma verdade aceita por todos, inclusive por mulheres: elas existem para servir aos homens [...] a cada gole de mulher, o homem sente-se, como em um ritual, mais homem. Conforme ele a engole, ela desaparece de cena para surgir a imagem de um homem satisfeito, feliz; afinal, matou sua sede. É um massacre simbólico ao feminino. É uma violência que alimenta e se alimenta da violência presente no cotidiano contra as mulheres (BENTO, 2007).

Ao retratar as crises existenciais vividas por mulheres em Mística Feminina, há um fenômeno relatado pela autora à supervalorização da imagem feminina de esposa e mãe e o desestímulo a uma vivência profissional-intelectual fora dos limites do lar. Quando aduz sobre o "problema sem nome" (FRIEDAN, 1971, p. 158), este acaba sendo a ordem direta do que se chamou de Mística Feminina.

Minha tese diz que o âmago do problema feminino não é de ordem sexual, e sim de identidade - uma atrofia ou evasão do crescimento, perpetuada pela mística. É minha tese que assim como a cultura vitoriana não permitia à mulher aceitar ou gratificar suas necessidades sexuais básicas, a nossa cultura não lhe permite aceitar ou gratificar a necessidade básica de crescer e alcançar sua plenitude como ser humano, necessidade que não se define unicamente pela função sexual. (FRIEDAN, 1971, p. 68).

Em suma, seja na década de 60 ou quase 60 anos depois, mulheres ainda não conseguem criar suas próprias identidades, e com isso sofrem o vazio existencial de uma vida ditada por padrões comportamentais, psicológicos e principalmente estéticos, de um universalismo que na verdade é uma grande fachada para a manutenção do patriarcado e da subjugação do gênero feminino.

Isto porque, a beleza não é um atributo ou qualidade universal, nem imutável. Tampouco configura-se a beleza como uma evolução de espécies, pois os seus ideais mudam a uma velocidade muito maior do que a evolutiva dos homens, tais padrões muito menos, são 
relacionados a reprodução per si. E então em que se baseia esse mito? Segundo Wolf (2018, p. 31) é composto de um distanciamento emocional, política, finanças e repressão sexual, nada tem a ver com mulheres e sim, centraliza-se em torno das instituições masculinas e do poder institucional de homens.

E são esses homens, por sua vez, que estão inseridos nos veículos de comunicação, que veiculam campanhas objetificantes e que controlam os padrões de consumo que são enviados a mulheres todos os dias. Exemplos como esses são vistos todos os dias, na indústria cinematográfica, por exemplo, onde as atrizes estonteantes de outrora atingem seu ápice aos 30, 40 anos e depois são substituídas por rostos mais jovens, como no "remake" do filme "As panteras" em que as atrizes originais, cuja idade mais avançada era de Cameron Diaz com apenas 40 anos, seriam substituídas, enquanto Tom Cruise está no sexto "Missão Impossível" aos 50 .

A construção de identidades então, torna-se um movimento necessário, o feminismo denota um movimento social e político que repensa e recria essas identidades, visando a valorização das qualidades femininas e buscando alcançar uma sociedade em que "as diferenças entre os sexos não se traduzam em relações de poder” (ALVES, p. 7-10).

É a própria utilização da linguagem dos direitos humanos em um sentido de "empoderamento" de identidades, de atos para a produção de uma nova consciência e que trazem consigo ações que tem um caráter emancipatório (MERRY, 2006).

Isso porque, muitos Estados se recusam a outorgar direitos as mulheres a partir do argumento de que isso atentaria contra a cultura e tradição, que ocasionaria conflitos sociais, e que a submissão feminina deve uma realidade legal e social, que a concessão de menos direitos é justa e que mulheres devem estar aptas ao matrimonio e reprodução (MERRY, 2006).

Os movimentos sociais contemporâneos e a filosofia política feminista implicam em resistência contra estes cenários, constituem ferramenta indispensável pela igualdade no poder, visando um cenário mais democrático de direitos para homens e mulheres, principalmente na aceitação da subjetividade em padrões estéticos.

A insurgência do feminismo demonstrou que as posições socialmente assumidas por cada sexo decorrem de construções ideológicas, que não necessariamente correspondem à equiparação real entre os gêneros, portanto os papéis sociais de homens e mulheres não seriam destinos biológicos, mas tão somente subprodutos culturais de uma relação de dominação que aparece de formas mais explícitas ou veladas, como os padrões midiáticos que exploram o corpo 
da mulher, o vendem e atingem continuamente a sua dignidade e, por conseguinte, violam direitos humanos.

A UNESCO, diante desse cenário, desenvolveu documento chamado "Plan Prioritario de Igualdad de Género 2008-2013" que propõe um roteiro a ser seguido no intuito de alcançar a igualdade de gênero no contexto midiático, entre as estratégias estão o combate ao uso de estereótipos, ou seja, narrar uma mulher a partir de um padrão físico, conjugal ou familiar, a menos que essencial para notícia ou propaganda. Além do que a elaboração de notícias ou propagandas que tenham sensibilidade com a questão de gênero. (MORENO, 2017)

Assim, é preciso combater o "mito da beleza" e a violação de direitos humanos das mulheres contidas nesse ideal, quer dizer separa-lo de tudo que mantém a mulher enquanto refém: sua sexualidade, vínculos entre as mulheres, prazer visual e sensual em tecidos, formas, cores, tudo aquilo que faz com que mulheres se sintam mal sobre si mesmas. (WOLF, 2018).

Padrões de beleza impõem a mulheres uma falsa escolha: ser sexy ou séria? Ser bonita ou feia? Magra ou gorda? Atributos são subjetivos, um aspecto do eu, não exclui o outro. Em um mundo onde mulheres possuem escolhas verdadeiras, escolhas acerca da aparência seriam apenas escolhas, e não custos de uma vida toda. Formas de expressão e não de tortura. É possível se vestir bem e ainda assim, saber expressar uma opinião, ou tampouco fazê-lo.

Deixar para trás as amarras da coisificação é poder estar livre dentro do próprio corpo, é intensificar o combate contra formas de beleza universalizadas, frias, cruas. É entender a diversidade da mulher, de suas curvas, de seus traços e de suas mentes não redutíveis a um só padrão, uma normatização do que deve ser seguido e cultivado, que obedece a uma cultura patriarcal que ainda quer estabelecer quem será a mulher.

A mídia, nesse contexto, pode e deve ser uma ferramenta para empoderamento e sororidade e não mais para a venda de estereótipos femininos "bem-sucedidos", garantindo as mulheres o direito de escolha da própria identidade.

\section{CONSIDERAÇÕES FINAIS}

Durante a última década, as mulheres abriram uma brecha na estrutura do poder. Conquistaram mais espaço no âmbito político, do trabalho, familiar e social. Ao longo dos anos, as mulheres, felizmente, têm se tornado mais independentes financeiramente, têm se libertado da mística feminina da domesticidade. Entretanto, ao mesmo tempo em que há essa libertação, 
mais o mito da beleza expande-se, enquanto a mística se definha, para realizar o controle social. Estamos, segundo Naomi Wolf (2018), em meio a uma violenta reação contra o feminismo. Quanto mais as mulheres empoderam-se e torna-se independentes financeiramente e socialmente, mais o mito da beleza se evolui.

A mídia, mediante os meios de comunicação como televisão, rádio e internet, dissemina o verdadeiro padrão da beleza. Mais mulheres são colocadas em patamares de destaque, já que se visualiza hoje, comumente, mulheres como protagonistas de novela, como âncoras de telejornais, bem como apresentadoras de programas de televisão. Entretanto, as mulheres disseminadas pela mídia são consideradas mulheres belas, magras, bem vestidas e maquiadas. A mulher com classe, independência e com o corpo perfeito. Esses padrões são disseminados como padrões ideais a serem seguidos por todas as mulheres para o alcance da felicidade e bem-estar.

Para alcançar o padrão de beleza ideal, as indústrias de dietas e cosméticos, bem com a indústria de vestuário, passaram a ser os novos censores culturais do espaço intelectual das mulheres (WOLF, 2018). A modelo jovem e esquelética tomou lugar da dona de casa feliz. Cada vez mais, as mulheres desembolsam dinheiro para alcançar o corpo perfeito, para realizar uma cirurgia plástica, para fazer tratamentos estéticos, para comprar maquiagem e roupas da moda. Há, verdadeiramente, um ciclo vicioso sem fim, pois a mulher contemporânea, influenciada pela mídia, que alcançar a felicidade e esta, só será alcançada através da beleza perfeita.

Há, verdadeiramente, um caminho sem fim. Ao repassar um ideal de beleza perfeito, a mídia incentiva as mulheres a correr atrás desse padrão aceito. Em razão da maioria das mulheres, principalmente as brasileiras, possuírem um estereótipo totalmente diferente daquele disseminado pela mídia, essas nunca ou dificilmente alcançarão o padrão de beleza disseminado. Com isso, sofrerão enormes distúrbios físicos, mas principalmente, psicológicos. Como mencionado no decorrer da pesquisa, muitas mulheres tornam-se anoréxicas ou bulímicas por não alcançar o peso ideal tão desejado e disseminado pela mídia.

Essa disseminação e a educação dessas mulheres com base em uma determinada beleza estereotipada acaba por provocar inúmeros distúrbios psicológicos, configurando-se uma violação de direitos humanos. A mulher, segundo o art. 6, b da Convenção de Belém do Pará, tem o direito de ser educada e valorizada livre de padrões estereotipados. A mesma convenção, como mencionado, considera como violação de direitos humanos, a violência psicológica 
praticada em desfavor dessas mulheres. Considera-se, portanto, que a disseminação de uma imagem perfeita, da felicidade vinculada a busca de um determinado padrão de beleza, representa uma clara evidencia da violência psicológica contra a mulher, representando, portanto, uma violação de direitos humanos, nos termos da Convenção de Belém do Pará.

Desta feita, além de uma maior representatividade à Convenção de Belém do Pará, seria necessário o estímulo para que as empresas de cosméticos e organizações feministas mostrem a perversidade da imposição de padrões estéticos e estimulem a mulher ser quem ela é, amando seus próprios defeitos e qualidades corporais. Conjuntamente a essas campanhas, para uma justa valorização da mulher, necessário se faz um trabalho de conscientização das mulheres. Estes seriam voltados para o mundo empresarial no sentido de que a imposição ou insinuação de um padrão próprio de beleza viola os direitos fundamentais da mulher com relação a igualdade de gênero, dignidade e liberdade, o que acaba dificultar a inclusão social feminina, provocando uma violação de direitos humanos, através da violência psicológica realizada.

A mulher contemporânea sofre um paradoxo promovido pela mídia e pelo capitalismo. Elas possuem a liberdade para serem o que quiserem, mas são dependentes da imagem repassada pelos meios de comunicação.

Ao mesmo tempo em que são livres, são dependentes da beleza disseminada, do corte de cabelo da moda, das roupas da moda, das cirurgias plásticas, da busca do corpo e do padrão de beleza perfeito. As mulheres são verdadeiras reféns da imposição do padrão de beleza ideal, são coisificadas e instrumentalizadas a representar, disseminar e vender uma beleza padronizada e irreal. Entram num caminho cheio de obstáculos em busca da felicidade e, consequentemente, da beleza perfeita. Ao adentrar nesse caminho, nunca saem, pois ele possui um início, mas não um fim.

E sobre essa imagem, enquanto violadora de direitos humanos, o "mito da beleza" que alimenta as mentes e corpos das mulheres a partir de uma imagem de feminilidade bemsucedida. Entender o papel da mídia é fundamental, para usá-la enquanto instrumento de empoderamento das mulheres através do feminismo e não como manutenção das relações de poder patriarcal. 


\section{REFERÊNCIAS}

ALMEIDA, Heloisa Buarque de. Consumidoras e Heroínas: gênero na telenovela. Revista de Estudos Feministas: Florianópolis, v.15, n. 1, 2007. Disponível em: http://www.scielo.br/scielo.php?pid=S0104-

026X2007000100011\&script=sci_abstract\&tlng=es Acesso em: 07 de setembro de 2018.

ALVES, Branca Moreira; PITANGUY, Jacqueline. O que é feminismo. Coleção Primeiros Passos. São Paulo: Abril Cultural/Brasiliense, 1985.

BENTO, Berenice. A Cerveja e o Assassinato do Feminino. Revista IHU - UNISINOS, Artigo publicado em 04 jan., 2007.

COMISSÃO INTERAMERICANA DE DIREITOS HUMANOS. Convenção Interamericana para Prevenir, Punir e Erradicar a Violência contra a Mulher, “Convenção de Belém do Pará". 1994. Disponível em: http://www.cidh.org/Basicos/Portugues/m.Belem.do.Para.htm. Acesso em: 05 de setembro de 2018.

ESCOLA SUPERIOR DE PROPAGANDA E MARKETING. A Verdade sobre a Beleza: um relatório global. $2007 . \quad$ Disponível em: http://www2.fiap.com.br/updown/upload_fiap/alunos/entregaTrabalho/arquivosAnexo/DOVE (1).pdf. Acesso em: 28 de agosto de 2018.

FRIEDAN, Betty. Mística Feminina. Petrópolis: Editora Vozes Limitada, 1971.

GOVERnO DO ESTADO DE SÃO PAULO. Distúrbio Alimentar Ameaça mais de 77\% das Jovens de São Paulo. 2014. Disponível em: http://www.saude.sp.gov.br/ses/noticias/2014/janeiro/disturbio-alimentar-ameaca-77-dasjovens-de-sp. Acesso em: 03 de setembro de 2018.

LIPOVETSKY, Gilles. A Felicidade Paradoxal: ensaio sobre a sociedade de hiperconsumo. São Paulo: Companhia das Letras, 2007.

MERRY, Sally Engle. Derechos Humanos, género y nuevos movimentos sociales: debates contemporâneos en antropologia jurídica. In: CHENAUT, Victoria; GÓMEZ, Magdalena; ORTIZ, Héctor; SIERRA, María Teresa (Coords.) Justicia y diversidad en América Latina. Pueblos indígenas ante la globalización. México/Ecuador: Ciesas/Flacso/La Casa Chata, 2011, p. 261-289

MORENO, Rachel. A Beleza Impossível: mulher, mídia e consumo. São Paulo: Editora Ágora, 2008.

MORENO, Rachel. A Imagem da Mulher na Mídia: controle social comparado. São Paulo: Editora Expressão Popular. 2017.

OLIVEIRA, Ana Carolina Lopes de. A Influência da Convenção de Belém do Pará na Prevenção da Violência Contra as Mulheres no Brasil, Chile e Guatemala. Brasília: 
Uniceub, 2017. Disponível em: < http://repositorio.uniceub.br/bitstream/235/11151/1/21391717.pdf >. Acesso em: 25 de agosto de 2018.

TORRECILHA, Júlia Céli. A mídia e as mensagens de gênero: uma perspectiva da mulher na sociedade de consumo. Dissertação apresentada ao Departamento de Jornalismo da Universidade Federal de Mato Grosso do Sul - UFMS, sob orientação do professor Álvaro Banducci. 2014. Disponível em <https://posgraduacao.ufms.br/portal/trabalhoarquivos/download/4715> Acesso em 20 ago. 2018.

VIANNA, Cynthia Semíramis Machado. Da Imagem da Mulher Imposta pela Mídia como uma Violação de Direitos Humanos. Revista da Faculdade de Direito UFPR, v. 3, n. 0, 2005.

WOLF, Naomi. O Mito da Beleza: como as imagens de beleza são usadas contra as mulheres. 1 ${ }^{\mathrm{a}}$ ed- Rio de Janeiro: Rosa dos Tempos, 2018.

ZÚÑIGA, Yanira. Ciudadanía y género. Representaciones y conceptualizaciones en el pensamento moderno y contemporâneo In: CULLETON, Alfredo; MAUÉS, Antonio; TOSI, Giuseppe; ALENCAR, Maria Luiza; WEYL, Paulo (Orgs.). Direitos humanos e integração latino-americana. Porto Alegre: Entrementes, 2011, p. 277- 296. 